\title{
CONGENITAL HEART BLOCK WITH DEXTROCARDIA
}

\author{
BY \\ DUNCAN LEYS \\ From the Highlands and Islands Medical Service \\ Received July 12, 1942
}

Stein and Uhr (1941), describing congenital heart block in a girl of 3, bring the total of reported cases to 55. Apparently the number that are recognized and reported is still not great, since Campbell and Suzman (1934) analysed 53 which they accepted as fulfilling the criteria of diagnosis. Associated anatomical defects of the heart always seem to be present, and, as might be expected, septal defects are common, if not invariable. It has not been suggested that any case of incomplete heart block is congenital: partial and transient heart block is, of course, common enough in the acute infections, but if it should become complete, the patient usually dies. Fishberg (1940) saw one patient who survived with complete block that was apparently due to diphtheria, and quotes Stechner's study of 19 others, all of whom died. White (1937) thinks acquired cases apart from coronary disease are rare. The age of the patient is therefore a fair indication of the ætiology of complete heart block that persists, i.e. coronary disease in middle age and congenital defect in childhood and early adult life, and this rule will be subject to few exceptions. Writers have rather tended to insist that the cause of complete heart block in children and young adults should be assumed to be infection unless there is proof of its congenital origin, and Yater (1939) gives several criteria for the diagnosis. It seems likely, however, that most, if not all, cases of complete heart block in children and young adults are congenital, and the mere history of a severe infectious disease is no proof of atiology. There must be few children in whom a history of one or other of the infectious diseases cannot be discovered, and one would need to have seen the appearance of block during the course of the infection to assume that this had been responsible. Such an observation, of course, has often been made in diphtheria, but survival after its appearance must be rare. The existence of any other evidence of congenital heart disease would be strong presumptive evidence that the heart block was also congenital. For example, Bower (1939) reports two cases as discovered after severe measles, but both had systolic murmurs that were probably due to septal defect.

A case of congenital heart block, with dextrocardia as part of a complete transposition of viscera, is here reported; she had the further peculiarity that she came under my notice with an acute primary tuberculous infection, and later developed extensive pulmonary tuberculosis, which, however, shows a strong tendency to heal. The association of complete heart block with dextrocardia must be very rare; I have only found reference to one other case (Yater, 1929). My patient had also the signs of septal defect.

Brown (1939), making a rather narrower selection of cases of complete heart block than that of Campbell and Suzman (1934), accepts 44 as being congenital, of which 27 had clear signs of a septal defect, confirmed in 5 by autopsy. He considers the rarity of congenital complete heart block fully explained by the fact that the A-V bundle develops in the fotus before the formation of the septum, so that a defective septum is unlikely to interfere with conduction. The heart rate is not so slow as it is in adult acquired block, and may increase to 80 under certain conditions. The ordinary ventricular rate at rest is usually about 50 ; it is more easily increased by stimuli than in acquired heart block, and this explains why, unless a special search is being made for such cases, the condition may easily be overlooked. The subjects of congenital heart block may pass through a medical examination without the block being discovered.

Case Notes. H. G., aged 20, was admitted to the Royal Northern Infirmary on July 11, 1939. Three weeks before, there had been an eruption on the legs described as " a few small hard red tender spots," and at the same time she had pain in the legs on movement; a week after this she had a succession of rigors and a pain in her chest with some shortness of breath. It had been known for some years that she had dextrocardia, and exertion had always made her breathless and cyanosed. There was no history of any relative having been affected in the same way. The parents were not related and had neither dextrocardia nor heart block. Information about other sibs was merely second-hand from the girl's mother, i.e. she had never heard of any congenital heart peculiarity. 
When admitted she had slight fever (temperature $99.5 \mathrm{~F}$.), but was in no discomfort. She was cyanosed, but respiration at rest was quite peaceful. There was obvious clubbing of fingers and toes. Complete transposition of viscera was present (Fig. 1). There was a dorsal scoliosis, the heart's apex

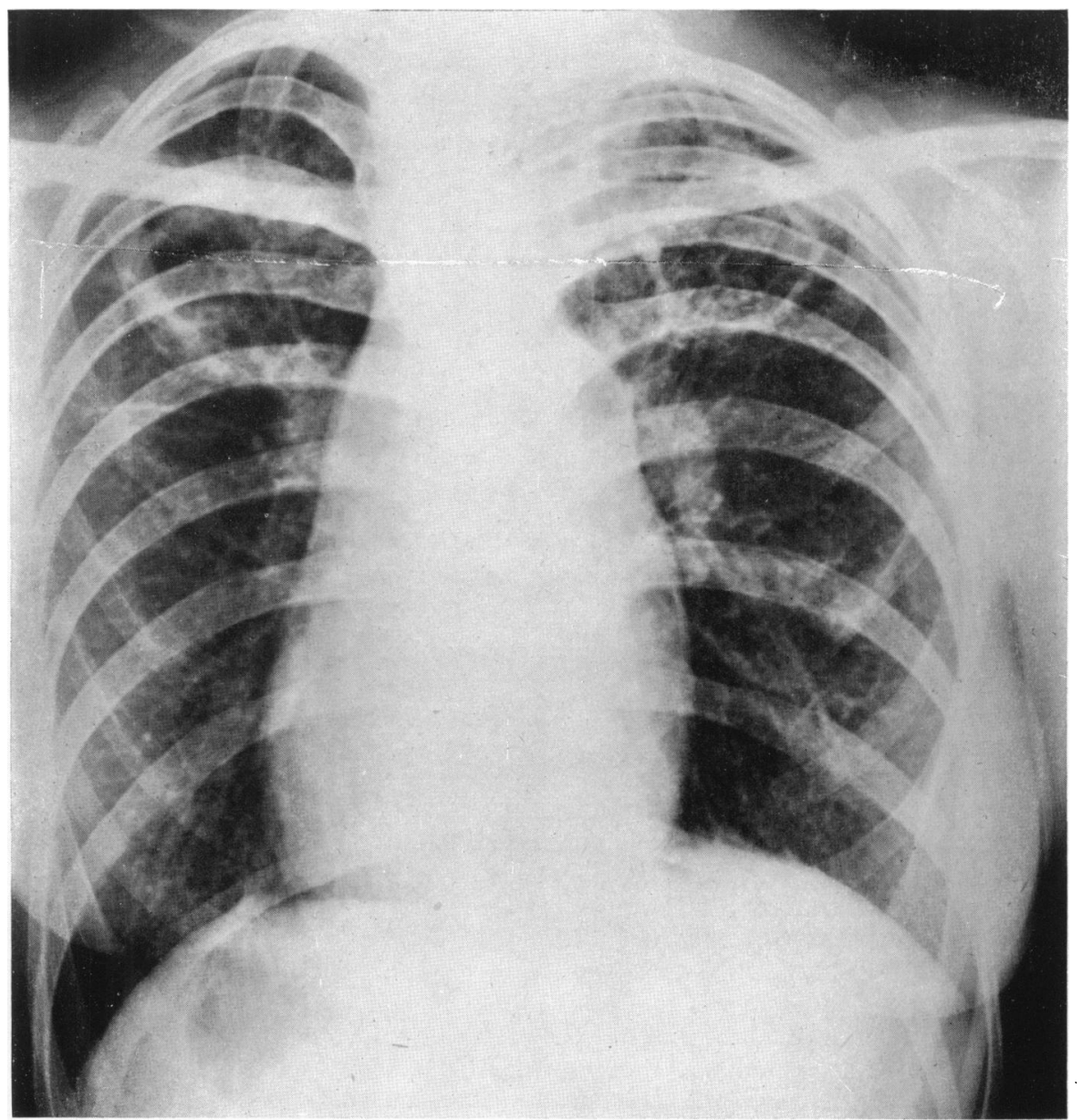

FIG. 1.-The chest in 1942, showing the development of tuberculous cavitation; there is also dextrocardia and enlargement of the "right" or pulmonary side of the heart, both of which had been present in the picture taken in 1939.

was to the right, and a loud rough systolic murmur was audible all over the præcordium with maximum intensity over the second right costal cartilage; there were no diastolic murmurs. The rhythm was regular, the rate 80 , and the blood pressure $110 / 60$ in the arms. The spleen and liver could not be felt, but there was dulness to percussion over the presumed site of the liver on the left side, and a small area of dulness over Gairdner's line (on the right side). No signs remained of the eruption on the legs and there were no petechial spots or hæmorrhages in the retina. A catheter specimen of urine showed a few red cells. The sedimentation rate (Westergren) was 80 and remained near this figure on repeated examination during her stay of four weeks in hospital; blood cultures were sterile. The cardiogram (Fig. 2) showed complete dissociation of auricle and ventricle, inversion of P I, and a deep Q I characteristic of the "mirror" picture of visceral transposition. T I, however, was positive. There was right axis deviation, which was consistent with hypertrophy of the pulmonary side of the heart due to septal defect.

The ventricular complex nowhere suggested an origin below the bifurcation of the bundle : this is to be expected, and is a usual feature of congenital heart block (Lampard, 1928). The auricular rate was $90-100$ and the ventricular, $45-50$.

The temperature fell to normal after 24 hours and the heart rate decreased until it reached its habitual frequency of 48 to 52 . Exercise and subcutaneous adrenalin had no influence on the heart rate. The patient went home, and was kept in bed for two months: I saw her again three months after she left hospital, when she was getting about, in no distress. 


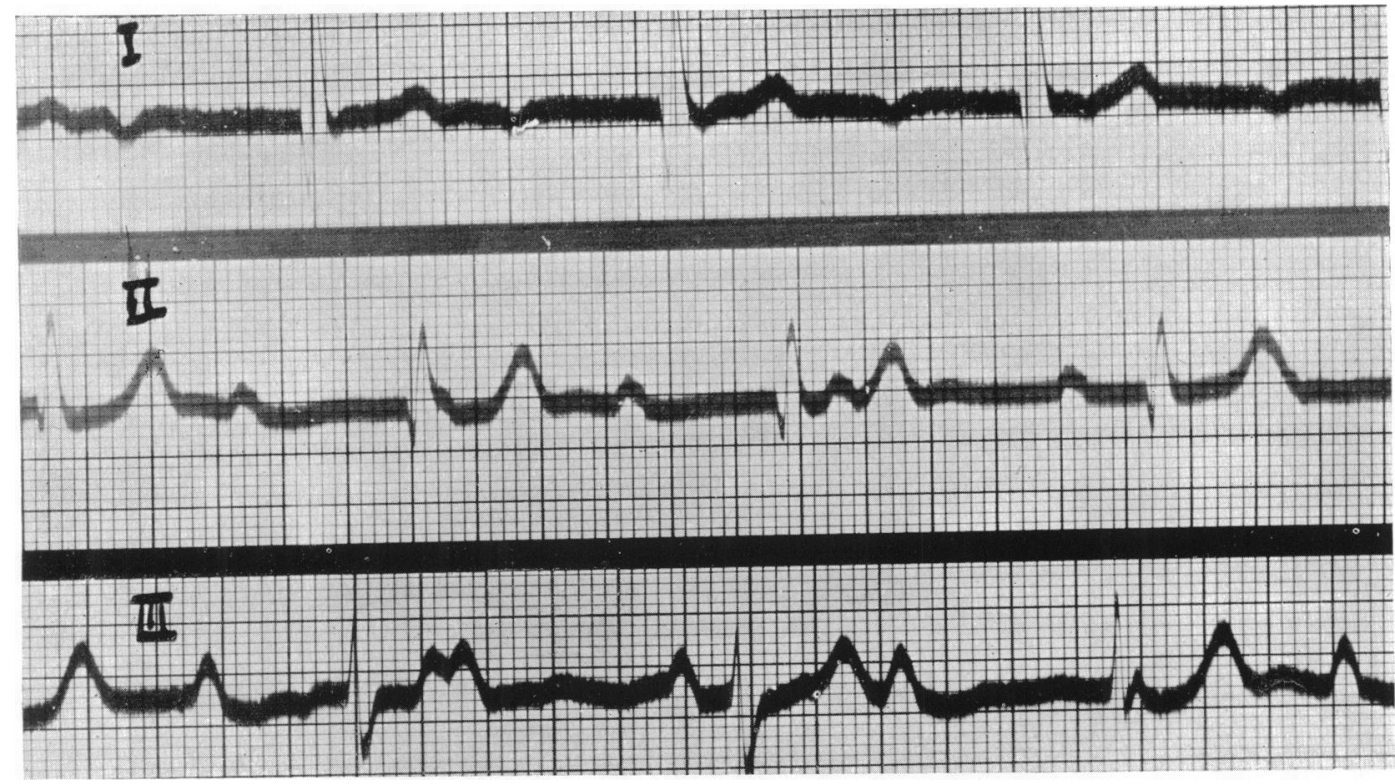

FIG. 2.-Standard leads showing dissociation of auricle and ventricle, inversion of $\mathbf{P}_{1}$, and right axis deviation.

I did not see her again until May, 1941, when hæmoptysis occurred: she had been working regularly as an accountant's clerk for more than 18 months, and was in good health until she was moved to a northern town in mid-winter, where the heating arrangements were poor in her lodgings: she developed a cold and cough, which continued for some weeks, when the sputum became frothy and bright red. No evidence of heart failure was found, and there were no definite signs to be made out in the lungs. She was reluctant to go to hospital but reported after some weeks, when an $X$-ray showed scattered infiltration in both lungs, and the sputum contained tubercle bacilli. The sedimentation rate was now 60 . She remained in hospital for two months during which time her sedimentation rate fell to 21 , and she then returned home, at her own desire, practically symptomless. Reviewed in July, 1942, her health was as good, she thought, as it had been before her first hæmoptysis; an X-ray showed cavitation in both upper lobes, but with a hardening of all the pulmonary shadows; there was no sputum, and the sedimentation rate was 15 .

Brown quotes Abbot (1927) for the maximum age attained in congenital heart block as 20 years. My patient is already 23 and, apart from her tuberculosis, is in good health. Except to anatomists and embryologists, the interest of the condition lies mainly in the effect on the subject's functional capacity. Most writers on the subject agree that the expectation of life is governed rather by the associated heart defects than by the block. While the relative inelasticity of the heart rate must obviously limit the subject's power of sustained muscular effort, the impossibility of damaging tachycardia may prevent some wear and tear.

\section{SUMMARY}

A patient with congenital heart block, dextrocardia, and probable septal defect is reported. She also developed extensive pulmonary tuberculosis, but showed a good tendency to recovery, and attained the age of 23 with good functional capacity equal to office work. Her ventricular rate was about 50 , but rose to 80 during fever: it was not influenced by exercise or adrenalin.

\section{REFERENCES}

Bower, H. J. (1939). Lancet, 2, 686.

Brown, J. W. (1939). Congenital Heart Disease. London.

Campbell, M. and Suzman, S. S. (1934). Amer. Heart J., 9, 304.

Fishberg, A. M. (1940). Heart Failure. London.

Lampard, M. E. (1928). Arch. Dis. Childh., 3, 212.

Stein, W. and Uhr, W. S. (1942). Brit. Heart J., 4, 7.

White, P. D. (1937). Heart Disease. New York.

Yater, W. M. (1929). 'Amer. J. Dis. Child., 38, 112. 